\title{
Flexible and Scalable Radio over Fiber Architecture
}

\author{
Sarra REBHI, Rim BARRAK, Mourad MENIF \\ Higher School of Communication of Tunis, University of Carthage, Ghazala Technopark, 2083, Ariana, Tunisia \\ sarra.rebhi@supcom.tn, \{rim.barrak, mourad.mnif\}@supcom.tn \\ Submitted September 11, 2018 / Accepted March 31, 2019
}

\begin{abstract}
In this paper, we investigate a scalable Radio over Fiber (RoF) system compliant to $5 G$ fronthauling requirements. The proposed RoF architecture is able to adjust the network resources and capacities to satisfy user demands in terms of service, data rate and bandwidth. The flexibility and the reconfigurability of the proposed topology are provided through the inclusion of flexible network nodes which are at the Central Office (CO), the Remote Node (RN) and the Remote Access Unit (RAU). The centralized management of the RoF system based on a Software Defined Networking (SDN) enables the monitoring of the overhaul RoF system and the reconfiguration of network nodes parameters.
\end{abstract}

The proposed RoF system architecture is designed to support multi-standard operation and mm-wave services. We investigated multi-service operation assuming high speed mm-wave service at $60 \mathrm{GHz}$ besides to conventional wireless services such as WiFi and WiMax. The introduced system is able to operate for different $R F$ bands $(2.4,5.2$ and $60 \mathrm{GHz}$ ) with various modulation schemas such as BPSK, QPSK, 16QAM and 64QAM, that may be associated to Orthogonal Frequency-Division Multiplexing (OFDM) and multidata rates up to 5 Gbps.

To validate the RoF system performances, we have considered the Error Vector Magnitude (EVM) and service constellation as figures of merit at the End User (EU). The simulated results testify the architecture viability.

\section{Keywords}

Radio over Fiber, mm-wave, flexible RoF, software defined networking, multi-services, multi-band

\section{Introduction}

The aim of futuristic Radio over Fiber (RoF) systems is to deliver a rich mix of conventional wireless services and high-bandwidth traffic to a huge number of users at a low cost benefiting from network resources shared between operators and service providers. The key motivation for the $5 \mathrm{G}$ mobile communication is the low cost, the high throughput and the flexible deployment.
The target of recent works dealing with RoF systems is to demonstrate multi-operability co-sitting emphasizing centralized topology and flexible architecture merit in addition to multi-service and multi-standard operations. The recent published flexible RoF system architecture [1], [2] involve a Central Office (CO), a PON network, a Remote Access Unit (RAU) and a User Equipment (UE). Some works [1], [3] integrate a Remote Node $(\mathrm{RN})$ previous to the RAU in charge of optical routing and wavelegnths multiplexing. The RN de-multiplexes wavelengths using an Arrayed Wavelength Grating (AWG) or a demultiplexer and routes individual channels to their corresponding RAU. The use of a RN provides flexibility to the RoF system and allows optimizing optical network resources distribution. In [4], the authors investigate a photonic dynamic channel allocation based optical-frequency-interleaved Dense Wavelength Division Multiplexed (DWDM) for RoF systems at mm-wave band. The proposed architecture assumes two types of RNs equipped with an Optical Cross Connect (OXC) for demultiplexing and multiplexing operation and they evaluate Bit Error Rate (BER) as a function of photodetected power while varying channels number.

The authors in [5] investigate efficient multiplexing scheme for wavelength-interleaved DWDM millimeter-wave RoF systems and propose a carrier subtraction technique that improves the optical link performance by reducing the carrierto-sideband ratio of the multiplexed channels. The use of an AWG provides flexibility to the RoF system and allows optimizing optical network resources distribution. In [6], [7], the authors focused on a multi-band multi-service cloud radio access network assuming a basic RoF architecture based on distinct optical wavelengths handling separately conventional wireless services (WiFi and WiMax) and mm-wave service. First, the data associated to the services WiFi and WiMax are combined and driven to a Mach-Zehnder Interferometer (MZI) modulator assuming Single Side Band (SSB) modulation. The mm-wave service is modulated through a Direct Modulated Laser (DML) and transported in the baseband to the RAU where it is converted to $60 \mathrm{GHz}$ band. The authors highlighted the centralized management operation and the feasibility of multi-operators co-sitting while sharing the $\mathrm{CO}$ resources and offering flexible operation. The work presented in [7] investigated a triple play services (WiFi, WiMax and $\mathrm{mm}$-wave service) assuming a Coarse-WDM (CWDM) 
architecture. The system performance was validated by measuring the Error Vector Magnitude (EVM) at the UE equipment assuming $5 \mathrm{~m}$ wireless propagation distance.

The aim of RoF community is to demonstrate RoF systems worth boasting high capacity applications and multiband operation relying on centralized architecture and the proposed architectures $[1,2,7]$ are basically assuming point to point link scenarios and disparate optical wavelength holding wireless radio services and the studies were provided to demonstrate the multi display operation although the high spectral efficiency and flexibility operation were not considered by most of the above mentioned works. The introduced systems are limited and do not treat network topology reconfiguration and high throughput process. The whole system topology (data plane and control plane) were not suggested in the state of the art works.

In recent works [8], [9], RoF technology is assumed an outstanding candidate for $5 \mathrm{G}$ small cell transport that offers high throuphput and dense coverage while presenting low latency. Several works [10], [11] were dedicated to the development of a unified $5 \mathrm{G}$ transport infrastructure and many researchers focused in particular on small-cell technologies. The finding of this work is the purpose of a generic RoF system composed by a scalable, flexible and high reconfigurable RoF core network which is managed by SDN control plane. The introduced RoF system is able to connect large number of RAUs and meeting futuristic wireless network specifications in terms of centralized operation, resource management, flexible deployment, scalability and high throughput. To highlight the introduced architecture benefits, we evaluated the RoF system performances in terms of EVM, constellation and cell coverage meeting $5 \mathrm{G}$ mobile requirements.

The paper is structured as follows. Section 2 details the proposed RoF architecture and underlines the scalability and the re-configurability of the proposed system. Section 3 exposes the design parameters of an RoF system developed for multi-service display. Simulation results of RoF system performances are reported in Sec. 4. Section 5 concludes the paper.

\section{RoF System Architecture}

RoF systems are deploying small cell concept to burst the network capacities and provide high throughput. Due to small cell range and mobility, traffic distribution between cells is disparate and requires multiple transmission techniques in the $\mathrm{CO}$. In futuristic wireless networks, small cells draw great interest and were investigated at macro-cells edge decreasing inter-cell interference and reducing power consumption in addition to improving quality of services. However, the proliferation of micro-cells requires centralized deployment, frequency planning, synchronization and cells coordination [12]. The incessantly growth of control data gives rise to the key role of control and management unit in futuristic wireless networks. SDN paradigm occurred as an innovative technology aiming to provide flexible network deployment and improve network performances [13], [14]. SDN concept is based on control plane and data plane segregation. The SDN technology is well suited to hierarchical configuration, management and centralized decision in addition to supporting hybrid and high throughput requirements. In this work, we proposed to adopt control plane and data plane segregation as provided by the SDN technology and futuristic wireless networks ( $4 \mathrm{G}$ and beyond). The centralized RoF topology fulfills with control plane requirements and SDN recommendations facilitating self-organization networks (SON), coordinated multi-point (CoMP) and whole network management. The RoF topology enables a full control on the network nodes and ensures a best system ruling and adaptation. In the proposed RoF system, the SDN control plane hosts several controls aiming to oversee the whole network based on measurements and monitoring tasks.

\subsection{Central Office Architecture}

The proposed architecture must guarantee services continuity until the EU. Therefore, the RoF network architecture must be reconfigurable, multi-service and multi-rate according to the user position relative to RAU antenna, the number of active user by radio cell and the requested services. The scalability and the reconfigurability of the proposed architecture are essentially accomplished at the CO. Benefiting from the centralized topology advantages, the $\mathrm{CO}$ performs a major role since it shelters the optical carrier generation, the wireless service modulation process, the routing tasks and the Centralized Network Management System (C-NMS).

The flexibility of the introduced RoF system is demonstrated firstly at the optical wavelength generation through the use of an Optical Flat Comb Source (OFCS). This device generates optical carriers with tight optical channels (up to $12.5 \mathrm{GHz}$ ) rising the optical spectral efficiency [15], [16]. By assuming that each OFCS could generate 20 flat carriers, the C-band (1530-1565 nm) would be covered using 16 independent OFCS. The proposed optical generation stage results in lower system implementation cost, lower power consumption, less overcrowding plant and better performance when compared to an equivalent design with multiple discrete lasers. Another key use for OFCS is the flexibility and the scalability aspect of the optical carrier source that settles the desired waveband by adjusting the wavelength of the $\mathrm{CW}$ laser and fixes optical carriers number and interspace by handling voltage levels at the Mach Zehnder modulator arms [16]. Thus, the proposed optical wavelengths source is scalable and fits the networks optical resource needs by adjusting the OFCS parameters.

The use of the OXC next to the OFCS ensures the switch of a single wavelength according to the C-NMS enquiry. The OXC includes a demultiplexer enabling carriers separation and a switching device as illustrated in Fig. 1. Such switch circuit ensures high-speed operation and keeps protocol transparency in addition to high performances and reliability process. 


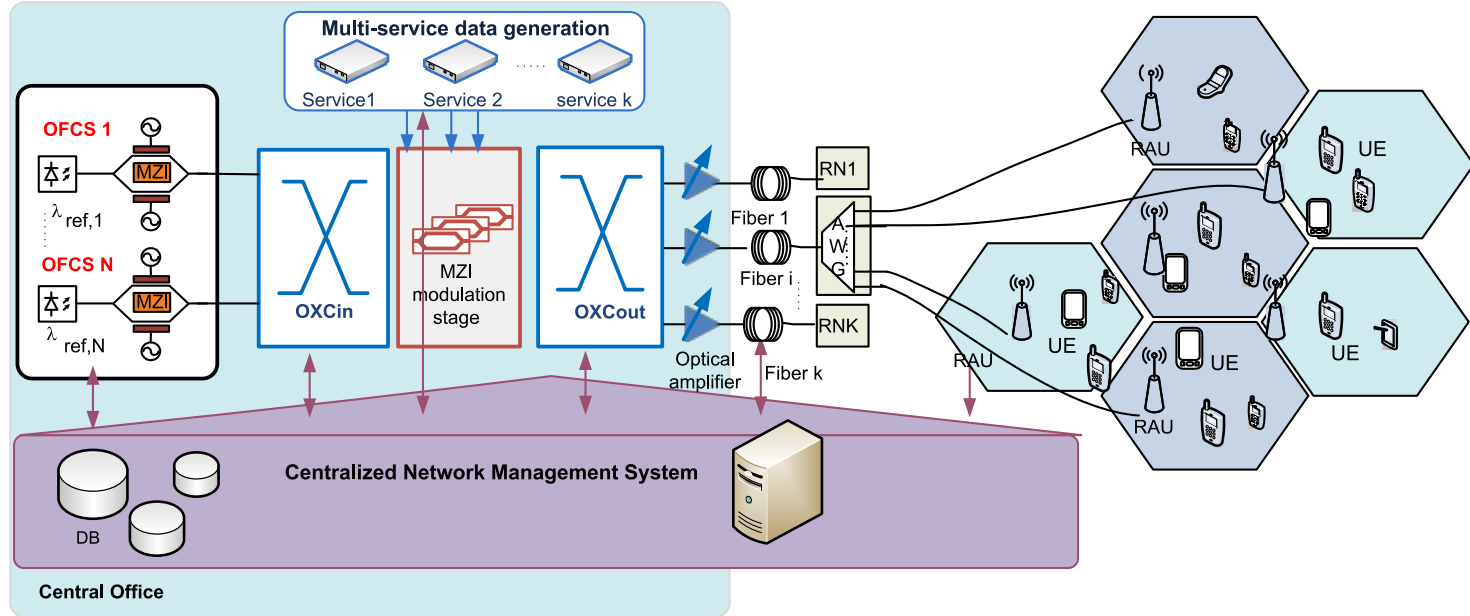

Fig. 1. Scalable and high throughput RoF system architecture.

The independent wireless services modulation process is crucial since it ensures RoF system scalability and adaptive modulation operation. The independent generated wireless services are combined together drive the appropriate MZI modulator in order to modulate the optical carrier. The modulated optical carriers pass through the second OXC stage where the modulated carriers are switched and redirected to the appropriate multiplexer assuring the combination of optical carriers routed to a specific RN.

\subsection{Remote Node Architecture}

The RN enables energy saving and routing flexibility. In recent works [17], [18], optical split power was proposed to route optical wavelength to the assigned RAU. However, this technique leads to huge power wasting and unbending optical system. To cope with such problem, we propose a RN architecture based on an AWG device used as either multiplexer or demultiplexer and responsible for optical wavelength assignment. In fact, the AWG device is passive and well suited for the RN deployment; also, it ensures accurate channel alignment and low crosstalk. The routing system flexibility owes to the AWG routing principle and the AWG periodicity or the Free Spectral Range (FSR) that depends on the AWG capacity $(1 \mathrm{xM})$, where $\mathrm{M}$ refers to the maximum number of output ports (channels).

The output port ( Port $_{\text {out }}$ ) address of an incoming signal with an incoming wavelength $\lambda_{\text {in }}$ is determined by [19]:

$$
\text { Port }_{\mathrm{out}}=\left(\text { in }- \text { Port }_{\mathrm{in}}+M\right) \bmod M
$$

where Port $_{\text {in }}$ refers to the input port address.

Hence, in an AWG device routing, a signal can actually reach any output port by properly controlling its wavelength $\lambda_{\text {in }}$. As depicted in Fig. 1, the monitoring of the output port and incoming wavelength would be very accurate and would make the routing tasks flexible and dynamic by simply controlling the incoming wavelength $\lambda_{\text {in }}$.
The cyclic periodicity FSR is equal to M times channel spacing. The incoming carriers centered at $\lambda_{\text {in }}$ and $\lambda_{\text {in }+ \text { FSR }}$ can be routed to the same output port. As a result, the cyclic FSR provides more flexibility to the device since each output channel receives $M$ different frequencies, one from each input channel [20]. Typical AWG devices operate in C and L bands and offer between $25 \mathrm{GHz}$ and $100 \mathrm{GHz}$ bandwidth with a capacity going up to 40 channels. Recent research efforts made it possible to develop $12.5 \mathrm{GHz}$ channel spacing AWG [21], [22] that enables the migration to high capacity WDM networks and compliant to flexible grid WDM [23]. In [21], the authors proposed 8 channels and $12.5 \mathrm{GHz}$ bandwidth spacing AWG based on small-bend structures using trenches filled with low-refractive index material and offering compact size compared with conventional AWG. Another research work [22] demonstrates an ultra-dense WDM PON network based on $12.5 \mathrm{GHz}$ channels AWG. The proposed component offers 256 channels raising the ultra dense WDM network capacity. The large variety of AWG capacities enable huge RAU links and provide fluidity to the networks planning and design. Furthermore, the flexible routing principle and the AWG FSR property optimize the routing function and emphasize the scalability of the introduced architecture. Hence, the use of AWG associated to a hybrid Time Division Multiplexing TDM-WDM access, enable high throughput and dynamic operation.

\subsection{Remote Access Unit Architecture}

The RAU is responsible for wireless transmission over the air. It is conceived to replace the base station functionalities in classical wireless networks. In the proposed architecture, the RAU functionalities are greatly simplified and are limited to the optoelectronic conversion and amplification tasks that lead to low implementation complexity and cost. The assigned optical wavelength $\lambda_{\text {in }}$ undergoes an AWG in order to separate services before converting them to RF signals. Each demultiplexed optical wavelength goes through a photodetector. 
The converted RF signals undergo separately amplification stage to reach the required transmit power. The RF amplification stage is composed by a Variable Gain Amplifier (VGA) that allows to amplify the RF signal according to the received signal power, modulation format and data rate. A high antenna gain contributes to improve network coverage.

\subsection{Centralized Network Management System}

Both high capacities and increasing network size increase the needed amount of control obviously. The centralized RoF design considerations are lined up with SDN requirements since Control plane and data plane segregation are greatly recommended by the SDN paradigm. The general SDN architecture [24] consists of three layers. The physical layer or data plane shelters logical network devices. The middle layer hosts SDN controllers that oversee traffic and supervise network behavior. The SDN applications layer communicate the network requirements and desired network behavior to the controllers.

Centralized management based on SDN owe to adapt resources, tune traffic priorities and adjust rate allowing scalable RoF system operation. Software based controllers allows granular control over users, network nodes and applications requirements. Accordingly, we assume SDN-controllers that make some measurements and supervise the network nodes performances as depicted in Fig. 2. The control layer analyzes and translates measurements into quality indicators then provide the SDN applications with an abstract view of the network.

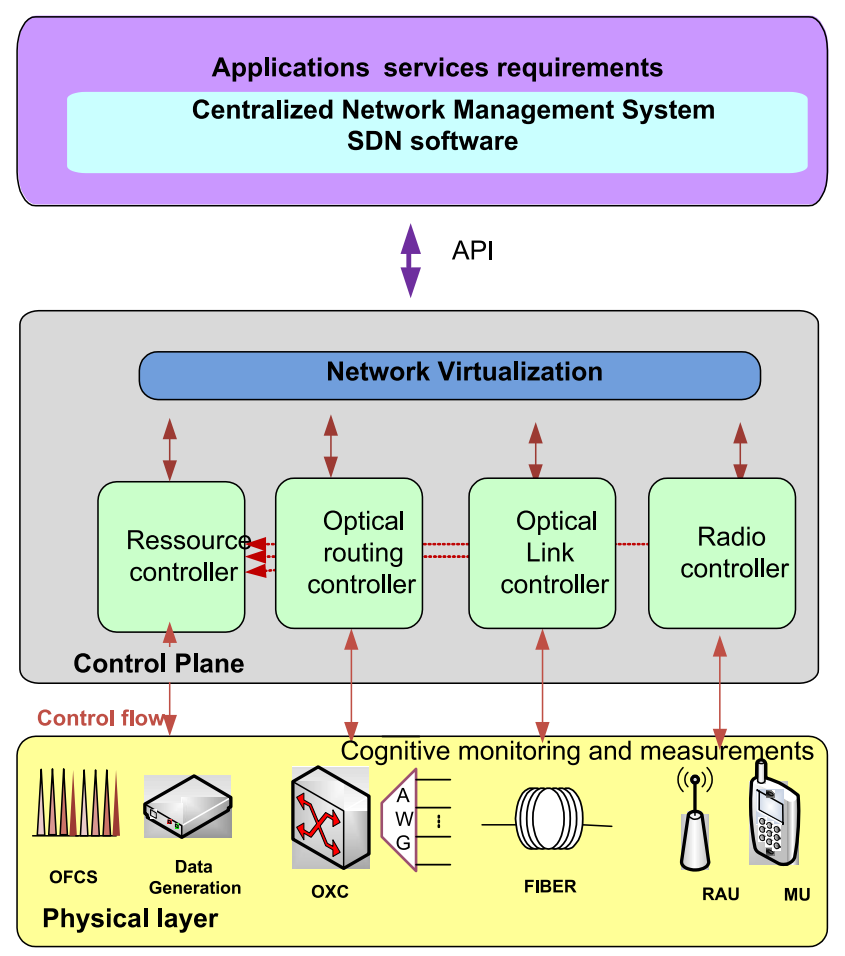

Fig. 2. Monitoring tasks, controllers and centralized decision using SDN paradigm.
Four types of controllers are used. We owe to use at least two controllers for optical and radio resources management. these controllers are allocated essentially at the optical carrier generation stage and at radio service generation block. The third class of controllers, located at the routing level, monitor the switching time and prevent network congestion. Several controllers are used to detect the optical transport link and the radio link; they perform some measurements, analyze it and forward it to the centralized system management updating the specific databases. The last class of controllers is employed to update parameters and adjust the optical and radio interfaces enabling efficient adaptation and reconfiguration actions. The C-NMS gather the incoming information, group it, and store it in specific databases. The collected information support to recognize the available resources and the possible adaptation. Hence, the C-NMS acknowledge a virtualized network behavior through recognizing the network state and holding the events historic. The C-NMS is responsible for centralized cognitive decision provided through the virtualization of the network configuration and the observation of the network behavior.

Therefore, the proposed RoF platform offer scalable and high reconfigurability skills and can integrate futuristic networks. The emerging mobile technology $5 \mathrm{G}$ networks asset the need of high capacities and dynamic optical networks. Accordingly, developing new backhauling and fronthauling solutions for metro/agregation segment and dense small cells deployment is considered as one of the most significant challenges for the upcoming $5 \mathrm{G}$ cellular systems [25]. RoF systems were presented as a prominent technology for $5 \mathrm{G}$ small cell transport since it is aligned with $5 \mathrm{G}$ target and challenges. In the most mentioned research works [26], [27], RoF is assumed a prominent fronthaul technology for $5 \mathrm{G}$ technology that could replace the popular digital fiber-optic interface Common Public Radio Interface (CPRI) due to stringent latency requirement (100-400 s). Therefore, RoF systems are considered a prominent candidate technology offering simplified design and low installation (CAPEX) and operation (OPEX) costs [28].

Thus, the proposed scalable RoF platform is lined up with $5 \mathrm{G}$ fronthauling technology requirements since it would provide several high speed applications, permit radio service aware transport and offer reconfigurabilitiy and scalabilitiy skills.

\section{RoF System Design}

In this section, we customized the generic RoF architecture for triple services display and we have assumed high optical spectral efficiency and high throughput scenarios enabling the evaluation of the RoF system performances. The target services are: WiFi, WiMax, and $60 \mathrm{GHz}$ high-speed mm-wave. Table 1 resumes $\mathrm{WiFi}$, WiMAX and mm-wave standard specifications as defined respectively by the standards 802.11g, 802.16m and 802.11ad [29-31]. 


\begin{tabular}{|l|l|l|l|}
\hline Services & $\begin{array}{l}\text { WiFi } \\
\text { (standard 802.11g) }\end{array}$ & $\begin{array}{l}\text { WiMax } \\
\text { (standard 802.16) }\end{array}$ & MM-wave (standard 802.11ad) \\
\hline Frequency band & $2.4-2.4835 \mathrm{GHz}$ & $5.25-5.35 \mathrm{GHz}$ & $56.16-64.8 \mathrm{GHz}$ \\
\hline Carrier frequencies & 14 channels : & 3 channels : & 4 channels: \\
& $2.412 \mathrm{GHz}, . .$, & $5.28 \mathrm{GHz}, 5.3 \mathrm{GHz}$, & $57.24 \mathrm{GHz}, 59.4 \mathrm{GHz}$, \\
& $2.484 \mathrm{GHz}$ & $5.32 \mathrm{GHz}$ & $61.56 \mathrm{GHz}, 63.72 \mathrm{GHz}$ \\
\hline Channel bandwidth & $20 \mathrm{MHz}$ & $20 \mathrm{MHz}$ & $2.16 \mathrm{GHz}$ \\
\hline Modulation & OFDM - BPSK, QPSK, & OFDM - BPSK, QPSK, & SC BPSK, QPSK, 16QAM, \\
& $16 \mathrm{AM}, 64 \mathrm{QAM}$ & $16 \mathrm{AM}, 64 \mathrm{QAM}$ & \\
\hline Data rates & Up to $54 \mathrm{Mbps}$ & Up to 73.19 Mbps & Up to $4.62 \mathrm{Gbps}$ \\
\hline Maximum transmit power & $30 \mathrm{dBm}$ & $36 \mathrm{dBm}$ & $10 \mathrm{dBm}$ \\
\hline Maximum allowed EIRP & $36 \mathrm{dBm}$ & $52 \mathrm{dBm}$ & $57 \mathrm{dBm}$ (Europe) \\
\hline
\end{tabular}

Tab. 1. WiFi, WiMax and MM-Wave standard specifications

WiFi standard was occurred for WLAN environment. Accordingly reachable wireless link are lined up with small cell requirements (around $100 \mathrm{~m}$ for outdoor applications and $27 \mathrm{~m}$ for indoor applications based on $802.11 \mathrm{~b} / \mathrm{g}$ standards [32]). Although, WiMax technology was essentially provided to support Internet Protocol Television (IPTV) applications and high speed internet. The 802.16 standard applications are rather prone to macro cell coverage up to several kilometers. In our study, we assume small cell scenario with line of sight propagation. Being based on the link budget equations provided in a recent work [33], we have calculated the theoretical radio link answering to medium range communications (cell coverage $<100 \mathrm{~m}$ ) for WiFi and WiMax flow. To achieve this goal, we fixed the transmit power to $10 \mathrm{dBm}$ for WiMax flow and $3 \mathrm{dBm}$ for WiFi services. The calculated theoretical radio distances for both services are around $85 \mathrm{~m}$. Hence, reducing transmit power streamline the radio stage by limiting amplification requirements.

We assume that mm-wave services deploy multi modulation schemas (B-PSK,Q-PSK, 16-QAM) with data rates up to $4.62 \mathrm{Gbps}$ as specified by the amendment of the standard IEEE 802.11ad. The WiFi and WiMax systems are deployed in their maximum flow (respectively $54 \mathrm{Mbps}$ and $73 \mathrm{Mbps}$ ). Table 2 defines Wi-Fi and WiMax OFDM parameters.

\begin{tabular}{|l|l|l|}
\hline \multirow{2}{*}{ Parameters } & \multicolumn{2}{|c|}{ Metrics } \\
\cline { 2 - 3 } & WiFi & WiMax \\
\hline $\begin{array}{l}\text { Number of } \\
\text { sub-carriers }\end{array}$ & 48 data +4 pilot & 192 data +8 pilot \\
\hline FFT size & 64 & 256 \\
\hline $\begin{array}{l}\text { Subcarrier } \\
\text { frequency spacing } \\
\left(\Delta(f)=F_{\mathrm{S}} / N F F T\right)\end{array}$ & $312.5 \mathrm{kHz}$ & $90 \mathrm{kHz}$ \\
\hline $\begin{array}{l}\text { OFDM symbol period } \\
\left(T_{\mathrm{S}}=T_{\mathrm{b}}+T_{\mathrm{g}}\right)\end{array}$ & $4 \mu \mathrm{s}$ & $1.22 \mu \mathrm{s}$ \\
\hline $\begin{array}{l}\text { FFT period } \\
\left(T_{\mathrm{b}}=1 / \Delta(f)\right)\end{array}$ & $3.2 \mu \mathrm{s}$ & $1.91 \mu \mathrm{s}$ \\
\hline Bandwidth & & $\left(T_{\mathrm{g}}=T_{\mathrm{b}} / 16\right)$ \\
\hline Modulation Scheme & $64 \mathrm{MHz}$ & $20 \mathrm{MHz}$ \\
\hline
\end{tabular}

Tab. 2. WiFi and WiMax OFDM parameters.
At the CO, the OFCS generates optical carriers from a continuous wavelength $(\mathrm{CW})$ light, with a $100 \mathrm{kHz}$ linewidth and a center frequency of $193.1 \mathrm{THz}$ (corresponding to $\lambda_{0}=1552.52 \mathrm{~nm}$ ). This optical signal is then injected into a dual-arm MZI modulator. Each branch is driven by in-phase sinusoidal signals at the required channel spacing $12.5 \mathrm{GHz}$ with specific amplitude difference. The $\mathrm{CW}$ light must be with large amplitude to generate highorder sidebands as indicated in [34]. The generated optical signals at $10 \mathrm{dBm}$ are de-multiplexed using 8 channel demultiplexer ( $25 \mathrm{GHz}$ bandwidth) in order to extract two optical wavelengths and process to signal modulation as depicted in Fig. 3. Demultiplexers with $25 \mathrm{GHz}$ bandwidth can extract two different optical carriers with $12.5 \mathrm{GHz}$ channel spacing. The two demultiplexed carriers are switched then redirected to an Optical Interleaver (IL) used in a reverse direction in order to separate the optical carriers into odd and even channels. The resulting optical channels have $12.5 \mathrm{GHz}$ of bandwidth. We propose to use interleavers with $25 \mathrm{GHz}$ channel bandwidth due to the scarceness of de-multiplexers with tighter bandwidth and lower cost. Even wavelength hold WiFi and WiMax data and odd wavelength hold mm-wave services. After the de-interleaving process, each optical carrier undergoes multi-band Single-Side Band (SSD) modulation using an MZI modulator.

WiFi and WiMax signals are OFDM 64-QAM modulated at respectively $54 \mathrm{Mbps}$ and $73 \mathrm{Mbps}$. WiFi signals are generated at $2.4 \mathrm{GHz}$ and $12.5 \mathrm{GHz}$ minus $2.4 \mathrm{GHz}$ bands, while WiMax signals are generated at $5.2 \mathrm{GHz}$ and $12.5 \mathrm{GHz}$ minus $5.2 \mathrm{GHz}$ bands. The WiFi and WiMax data are mixed together and then used to modulate the wavelength $193.1 \mathrm{THz}$ by using a MZI modulator. The MZI modulator is biased at $1 \mathrm{~V}$ reducing sidebands harmonics. The RF signal driving the arms of MZI is phase quadrature shifted generating SSB modulation.

The combined IF frequencies $(7.24 \mathrm{GHz}, 9.4 \mathrm{GHz}$, $1.56 \mathrm{GHz}, 3.72 \mathrm{GHz}$ ) corresponding to mm-wave radio channels drive the MZI modulator in order to modulate the optical wavelength $193.1125 \mathrm{THz}$ using SSB modulation. The modulated wavelengths $(193.1 \mathrm{THz}$ and $193.1125 \mathrm{THz})$ are combined through an ideal multiplexer. The multiplexed op- 


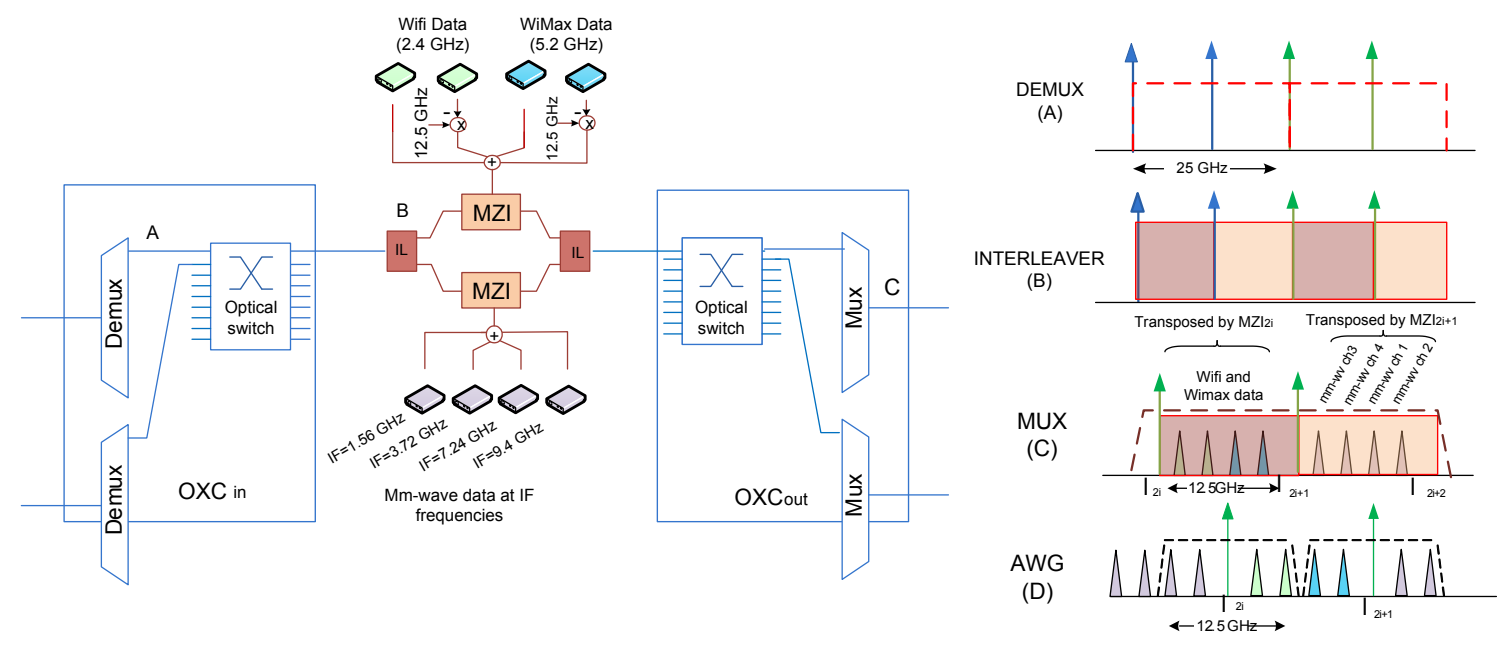

Fig. 3. Cross connect, modulation stage architecture and frequency planning of WiFi, WiMax and mm-wave services.

tical carrier pass through a $25 \mathrm{GHz}$ multiplexer as depicted in Fig. 3 then get amplified and transported over $20 \mathrm{~km}$ of Non-Zero Dispersion Shifted optical Fiber (NZDSF). The NZDSF fiber is suitable for low chromatic dispersion, high capacity and tight optical channel transmission. Table 3 resumes the used optical components specifications.

Assuming a BER equal to $10 \mathrm{e}^{-12}$, the received optical power is around $-7 \mathrm{dBm}$ as given by Fig. 4. Accordingly, we opt for an Optical Gain Clumped-Erbium Doped Fiber Amplifier (OGC-EDFA) offering $11 \mathrm{~dB}$ gain in order to boost the optical input power and drive the fluctuation of the fiber transported traffic.

\begin{tabular}{|l|l|l|}
\hline $\begin{array}{l}\text { Optical } \\
\text { component }\end{array}$ & Sub-items & Values \\
\hline Laser for OFCS & Frequency & $193.1 \mathrm{THz}$ \\
& $\begin{array}{l}\text { Power } \\
\text { Linewidth }\end{array}$ & $10 \mathrm{dBm}$ \\
\hline Mux/Demux & Bandwidth & $25 \mathrm{GHz}$ \\
& Insertion loss & $4 \mathrm{~dB}$ \\
& Filter type & Gaussian (2nd order) \\
\hline Interleavers & Insertion loss & $2 \mathrm{~dB}$ \\
1 and 2 & & \\
\hline MZM modulator & Extension ratio & $40 \mathrm{~dB}$ \\
& Switching RF & $2 \mathrm{~V}$ \\
& Modulation & $1 \mathrm{~V}$ \\
& voltage & \\
& Insertion Loss & $4 \mathrm{~dB}$ \\
\hline EDFA amplifier & Gain & $11 \mathrm{~dB}$ \\
& Saturation power & $17 \mathrm{dBm}$ \\
& Noise Figure & $3 \mathrm{~dB}$ \\
\hline NZSDF Fiber & Length & $20 \mathrm{~km}$ \\
& Attenuation & $0.2 \mathrm{~dB} / \mathrm{km}$ \\
& Dispersion & $2 \mathrm{ps} / \mathrm{nm} . \mathrm{km}$ \\
\hline AWG1 & Bandwidth & $12.5 \mathrm{GHz}$ \\
& Insertion loss & $4 \mathrm{~dB}$ \\
& Filter type & Gaussian (2nd order) \\
\hline AWG2 & Bandwidth & $6.25 \mathrm{GHz}$ \\
& Insertion loss & $4 \mathrm{~dB}$ \\
& Filter type & Gaussian (2nd order) \\
\hline
\end{tabular}

Tab. 3. Key parameters for simulated optical components.
We used an AWG to de-multiplex wavelengths at the RN routing individual channels to the correspondent RAU. Arriving to the RAU, the incoming wavelength undergoes a second AWG in order to retrieve individual services ( $\mathrm{WiFi}$, WiMax and mm-wave services). The upper sideband of the signal is converted to RF signals using an APD photodetector (with $6 \mathrm{GHz}$ bandwidth) to recover WiFi and WiMax traffics. WiFi signal pass through a band-pass filter centered at $F_{\mathrm{c}}=2.4 \mathrm{GHz}[35]$ and then undergoes $23 \mathrm{~dB}$ gain amplification stage to reach $3 \mathrm{dBm}$ transmit power [36]. WiMax signal goes through a band-pass filter centered at $F_{\mathrm{c}}=5.2 \mathrm{GHz}$ [37] and then undergoes a power amplifier [38] in order to reach $10 \mathrm{dBm}$. WiFi and WiMax signals are propagated through a $7 \mathrm{dBi}$ gain omnidirectional dual-band antenna $(2.4 / 5 \mathrm{GHz})$ [39]. We assume radio channel attenuations at 2.4 and $5 \mathrm{GHz}$ appropriate to free space loss in a hotspot indoor environment.

To generate mm-wave channels at $60 \mathrm{GHz}$ band, we beat channel \#1 and channel \#2 with a wavelength $\lambda_{j}$ generated by a laser at $R A U_{2 i}$ and spaced by $50 \mathrm{GHz}$ from wavelength $\lambda_{2 i}$ and to obtain channel\#3 and channel\#4, we beat the arriving wavelength at $R A U_{2 i+1}$ with a wavelength $\lambda_{k}$ spaced by $60 \mathrm{GHz}$ from $\lambda_{2 i+1}$.

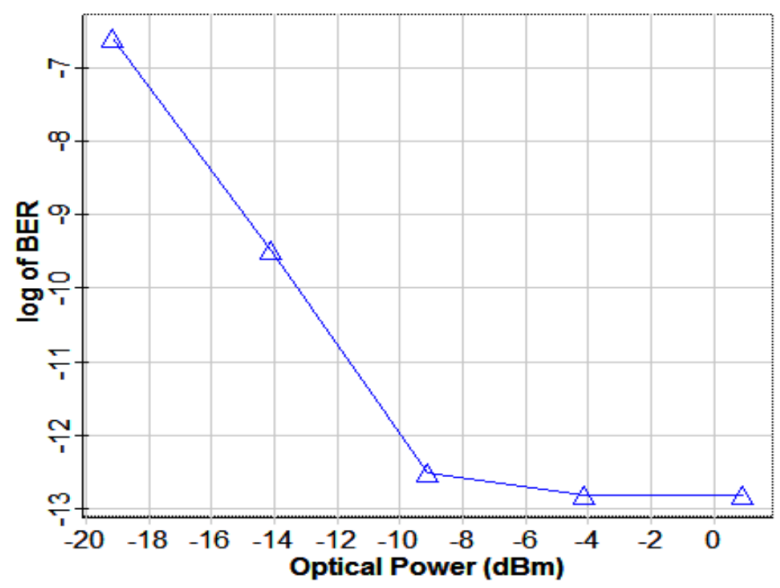

Fig. 4. BER as a function of optical received power. 


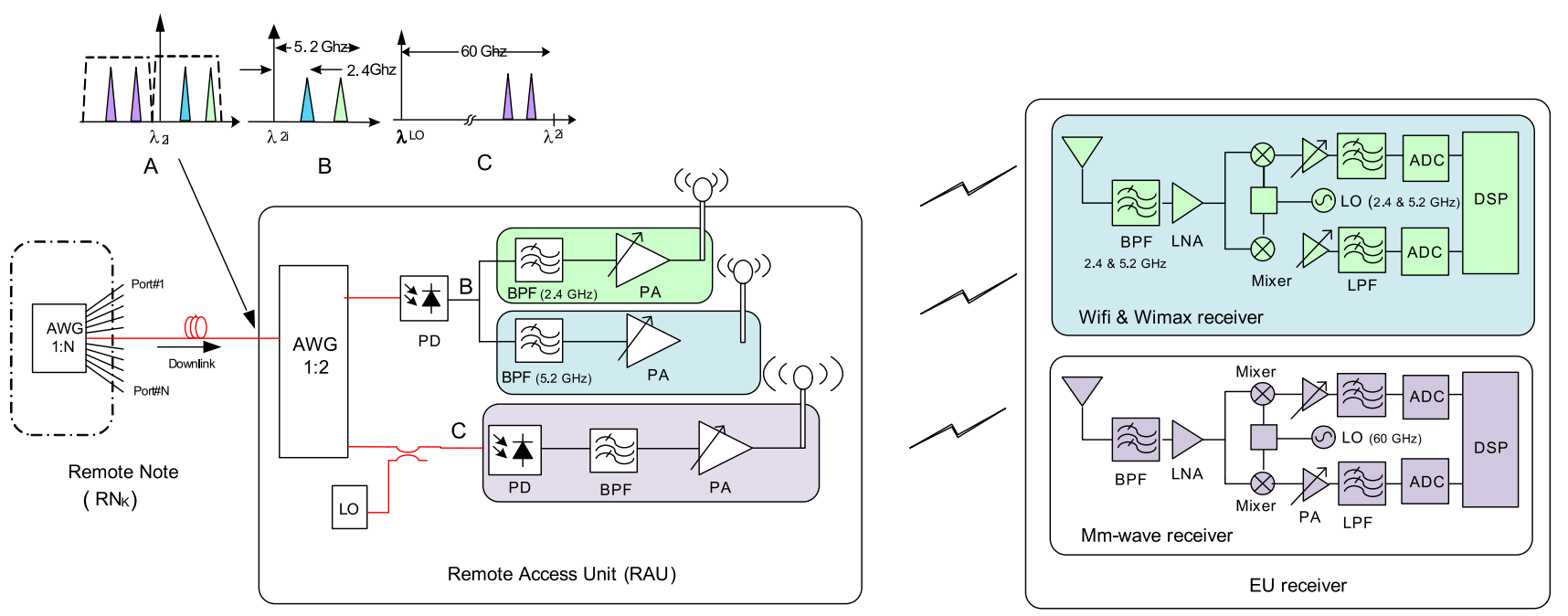

Fig. 5. Remote node $(\mathrm{RN})$, remote access unit (RAU) and end user (EU) architectures.

The mm-wave signals obtained at the output of the photodetector undergo a band-pass filter $(57-66 \mathrm{GHz})$ to select the required mm-wave channel [40] then pass through several amplifiers to bring the mm-wave signal to the spread power $(10 \mathrm{dBm})$. We owe to use a VGA that drive the power according to data modulation. The amplification stage is composed of two amplifiers: the first amplifier provides $18 \mathrm{~dB}$ gain [41] then second one afford $20 \mathrm{~dB}$ gain [42]. We opt for a $16 \mathrm{~dB}$ transmit antenna gain [43]. In the actual study, we neglect the multi-propagation impact investigated in previous work [44] and we assume line of sight scenarios based on a simple model of radio propagation that counts only free space losses and absorption attenuation.

At EU mobile, two wireless receivers are available as depicted in Fig. 5. At the mm-wave receiver, the $60 \mathrm{GHz}$ signal is captured using an $8 \mathrm{~dB}$ antenna gain [45], the target signal pass through a band-pass filter $(57-66 \mathrm{GHz})$ then get amplified using a dual-stage LNA having $14.5 \mathrm{~dB}$ gain each [46]. The resulting signal is down converted to baseband by using a quadrature mixer [47] and a local oscillator centered around $60 \mathrm{GHz}$ [48]. At baseband, I and Q signals undergoes a $14.5 \mathrm{~dB}$ variable gain amplifier [49]. The selected analog to digital converter (ADC) [50] has an input bandwidth up to $1.5 \mathrm{GHz}$, a maximum sampling rate of $10 \mathrm{GHz}$ and 10 bits resolution.

For WiFi and WiMax data, we assume a common directional antenna $(2.4 / 5 \mathrm{GHz})$ offering $6.5 \mathrm{dBi}$ gain [51], followed by a dual band-pass filter centered at $F_{\mathrm{c}}=2.45 / 5.5 \mathrm{GHz}$ with corresponding bands (2.4-2.48 GHz/5.18-5.79 GHz) [52], then we owe to use a $29 \mathrm{~dB}$ gain dual band LNA [53]. We investigate direct down-conversion architecture using dual-band voltage controlled oscillator [54]. At baseband, a low-pass filter followed by a variable gain amplifier [49] is used. The resulting signal is converted to digital to perform OFDM demodulation.

\section{Simulation Results}

In this section, we have simulated the whole downlink system (optic and radio links). We used Optiwave to generate wireless services (WiFi, WiMax and mm-wave) assuming random bits generation and simulate the optical system (wavelength generation, electro-optic modulation, Mux and Demux stages, the transport fiber link, the photo-detection stage). We developed on Advanced Design System (ADS) software the model of the RAU, the radio propagation channel and the EU mobile receiver. The RoF architecture was designed based on the frequency planning and standard specifications detailed in Sec. 3. We also assumed radio components specifications (amplifiers, antennas, filters, etc) selected from the state of the art and listed in the previous section. The co-simulation between the software (Optiwave and ADS) enables the evaluation the whole network performances.

To demonstrate system feasibility, we visualized the signal spectrum evolution over the RoF system. This is depicted in Fig. 7 and Fig. 6. Figure. 7(a) shows the generated wavelengths by the OFCS at the $\mathrm{CO}$ and Fig. 7(b) shows a resulting single optical wavelength after demodulation. The generated Wi-Fi and WiMax signals are depicted in Fig. 7(c) and (d) respectively. All the modulated wavelengths undergo through a multiplexer and we noticed a high spectrum efficiency as shown in Fig. 6(a). The optical carrier $193.1 \mathrm{THz}$ holds the combined mm-wave data at IF frequency assuming SSB modulation and the optical carrier $193.1125 \mathrm{THz}$ transports the mixed WiFi and WiMax sub-carriers obtained at the output of the MZI modulator. At the RN, each wavelength is retrieved as depicted in Fig. 6(b). By using an AWG, we achieve high wavelength selectivity, each wavelength is carrying WiFi, WiMax and mm-wave services. The photodetected WiFi and WiMax signals at $2.4 \mathrm{GHz}$ and $5.2 \mathrm{GHz}$ are depicted in Fig. 6(c). 

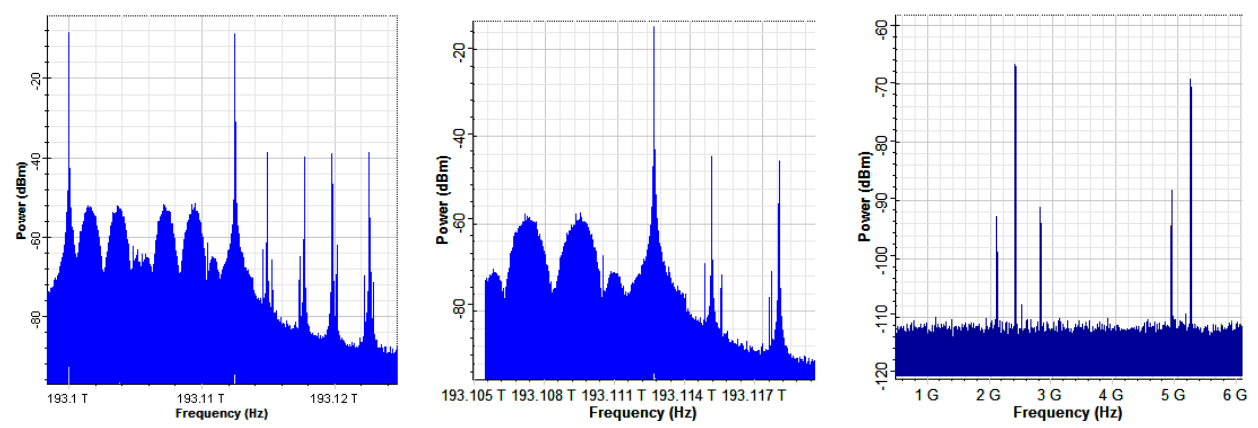

Fig. 6. (a) Mixed optical wavelength, (b) Demultiplexed optical wavelength, (c) Recovered WiFi and WiMax data.
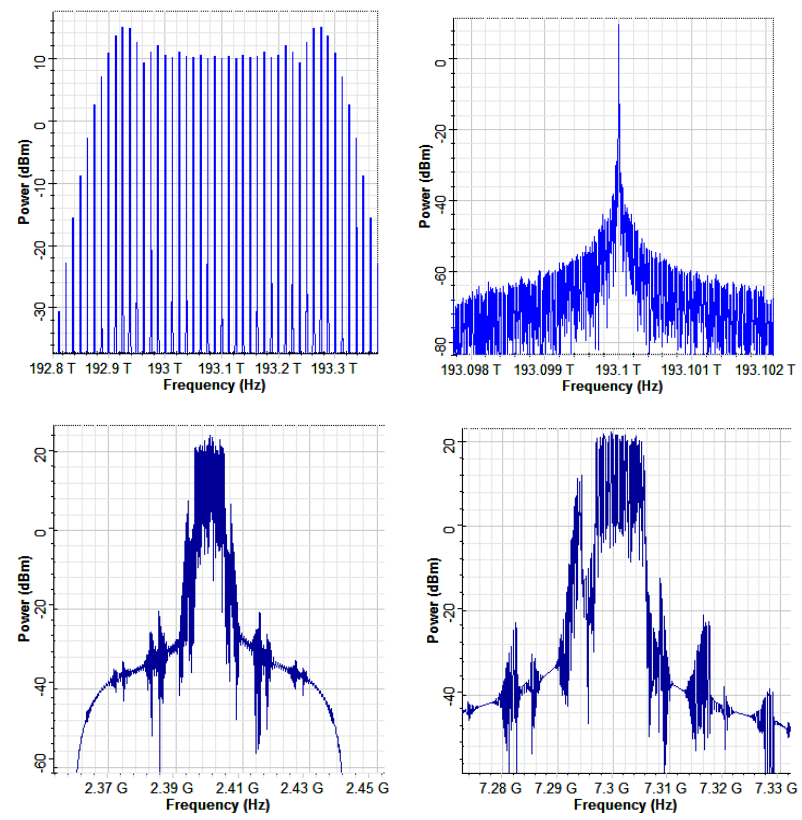

Fig. 7. (a) Generated wavelength using OFCS, (b) Resulting single wavelength, (c) Generated WiFi signal at $2.4 \mathrm{GHz}$, (d) Generated WiMax signal at $7.3 \mathrm{GHz}$.

The aim of this work is to demonstrate the scalability of the proposed architecture and its ability to support high throughput without performances deterioration. We have evaluated the constellation for WiFi and WiMax data assuming triple play service (WiFi, WiMax and mm-wave service) and simulate EVM performances for mm-wave data at the EU mobile as a function of the radio link by assuming several scenarios (number of data channels) and free space loss propagation model. Figure 8 and Figure 9 evaluate WiFi and WiMax constellations as a function of the radio link assuming triple play services (WiFi, WiMax and mm-wave service) and small cell environment (coverage cell < $100 \mathrm{~m}$ ).

The configuration includes: WiFi data $\left(F_{\mathrm{c}}=2.412 \mathrm{GHz}\right)$ assuming OFDM 64QAM modulation, WiMax data $\left(F_{\mathrm{c}}=5.2 \mathrm{GHz}\right)$ assuming OFDM 64QAM modulation and mm-wave flow 16QAM modulated at $4.62 \mathrm{Gbps}$. We have simulated the constellations for WiFi and WiMax data as a function of radio link range.
Figure 10 illustrates the evolution of EVM performances as the function of wireless radio link and RoF system capacity (number of holded mm-wave channels) and depicts the rank of the radio communication by considering a given EVM limit for each modulation format (BSPK, QPSK, 16QAM). We note that the simulated EVM at the EU receiver fulfills the EVM thresholds for different mm-wave modulation schemas. Assuming these thresholds, wireless radio link reaches significant ranges that respond to WLAN environment requirements. The small gap between simulated results and theoretical distances might due to the fact that the standard 802.11ad adopts bits (FEC) error correction decreasing defaults bits and improving the quality of link. We note that when increasing system capacity through increasing channels data and hence global network throughput, the RoF architecture performances are held and the EVM performance is not deteriorated. As a result, the use of the proposed architecture at the full capacity does not extensively impact the radio distance link as depicted in Fig. 10(a), Fig. 10(b) and Fig. 10(c).

The simulated radio distances for diverse modulation formats (BPSK, QPSK and 16QAM) are matched with calculated results as depicted in Tab.4. The gap between calculated radio distance and simulated radio distance for EVM limit are admissible assuming whole RoF system and high throughput. The most affected flow is the 16QAM modulated data (14 $\mathrm{m}$ and $5 \mathrm{~m}$ respectively for calculated and simulated radio link distances). This is probably due to the susceptibility of the 16QAM modulation to inter-modulation, noise and attenuation. However, the simulated distance is lined with RoF studies especially in [7].

\begin{tabular}{|l|l|l|l|}
\hline & BPSK & QPSK & 16QAM \\
\hline EVM limit [55] & $-11 \mathrm{~dB}$ & $-13 \mathrm{~dB}$ & $-20.5 \mathrm{~dB}$ \\
\hline $\begin{array}{l}\text { Throughput per } \\
\text { 12.5 GHz optical channel }\end{array}$ & $5 \mathrm{Gbps}$ & $10 \mathrm{Gbps}$ & $18.48 \mathrm{Gbps}$ \\
\hline $\begin{array}{l}\text { Calculated radio link } \\
\text { distance [33] }\end{array}$ & $44 \mathrm{~m}$ & $32 \mathrm{~m}$ & $14 \mathrm{~m}$ \\
\hline $\begin{array}{l}\text { Simulated radio link } \\
\text { distance assuming full } \\
\text { capacity architecture }\end{array}$ & $39 \mathrm{~m}$ & $27 \mathrm{~m}$ & $5 \mathrm{~m}$ \\
\hline
\end{tabular}

Tab. 4. Simulated RoF system performances. 


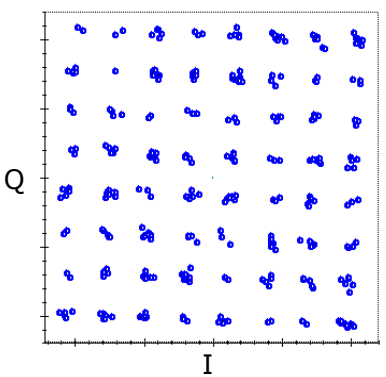

(a)

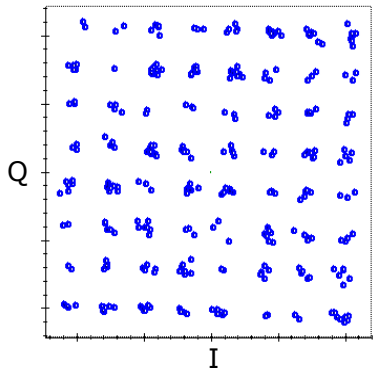

(c)

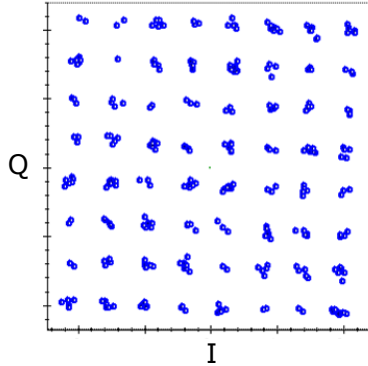

(b)

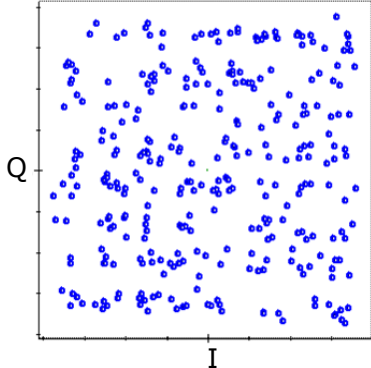

(d)

Fig. 8. Constellation of WiMax signal (64QAM modulation) assuming (a) $20 \mathrm{~m}$, (b) $40 \mathrm{~m}$, (c) $60 \mathrm{~m}$ and (d) $80 \mathrm{~m}$ radio link distance.

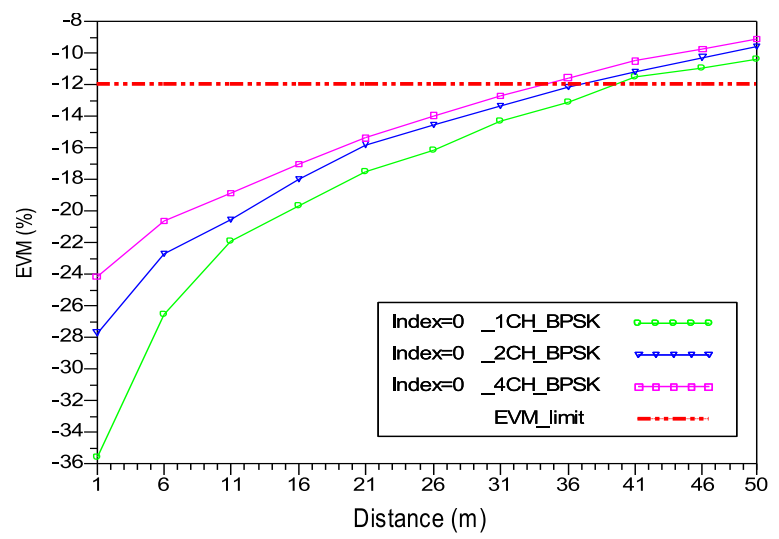

(a)

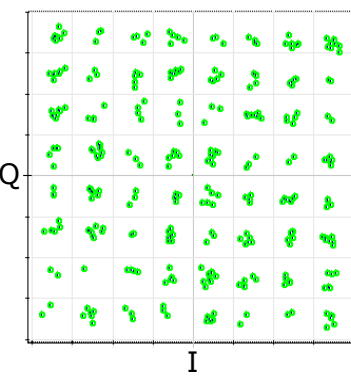

(a)

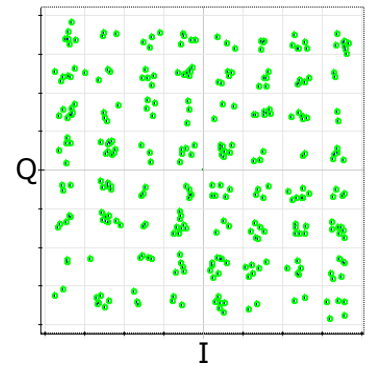

(c)

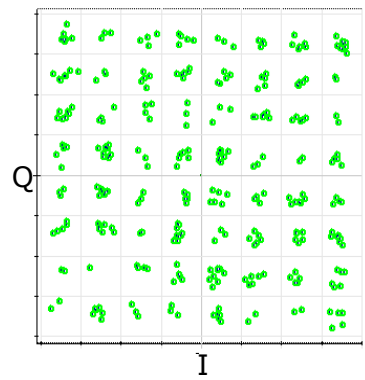

(b)

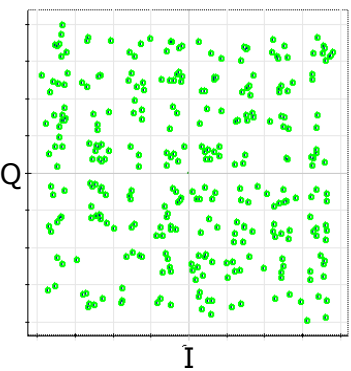

(d)

Fig. 9. Constellation of WiFi signal (64QAM modulation) assuming (a) $20 \mathrm{~m}$, (b) $40 \mathrm{~m}$, (c) $60 \mathrm{~m}$ and (d) $80 \mathrm{~m}$ radio link distance.

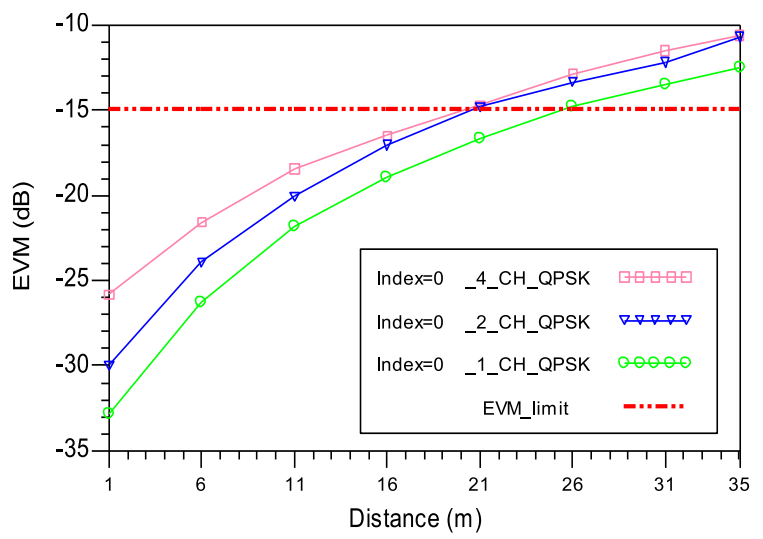

(b)

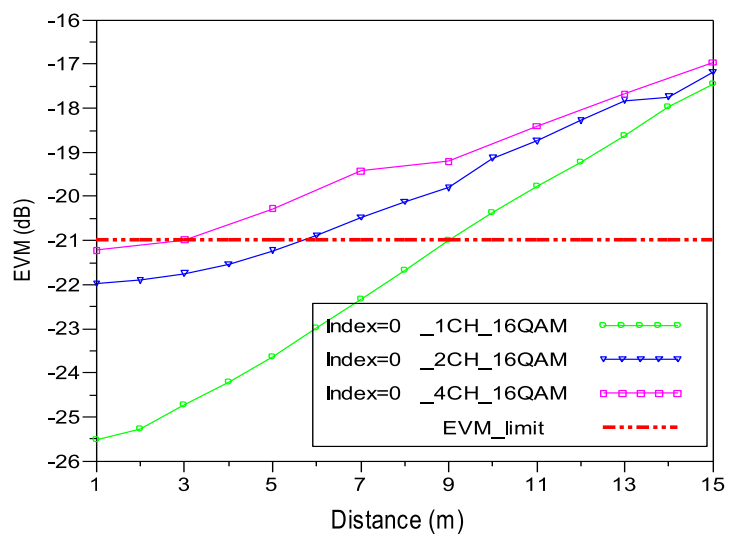

(c)

Fig. 10. EVM versus wireless link for (a) BPSK modulated mm-wave signal, (b) QPSK modulated mm-wave signal at 2.5 Gbps, (c) 16QAM modulated mm-wave signal at $4.62 \mathrm{Gbps}$. 


\section{Conclusion}

In this paper, we have proposed a scalable and high throughput RoF platform composed of a dynamic and flexible RoF architecture and a centralized management system based on SDN paradigm. The scalability of the architecture appears through the monitoring of the optical flat comb sources by adjusting the generating optical wavelength inter-space and the use of IF frequencies according to data requirements. The scalable topology occurs to fairly manage network resources, satisfy the network capacity growth and emphasize flexible deployment.The SDN-management is fundamental for decision making and RoF system parameters adaptation.

The proposed RoF platform was customized mutliservice and multi-standard RoF system. We investigated conventional wireless services: $\mathrm{WiFi}$ and WiMax data in addition to mm-wave service and demonstrate successfully the operation of the proposed RoF architecture. We evaluated mm-wave services by simulating the EVM assuming multi-format modulations (BPSK, QPSK and 16QAM) with data rates up to $5 \mathrm{Gbps}$. The EVM was simulated for $20 \mathrm{~km}$ of Non-Zero Dispersion Shifted optical Fiber and a variable wireless link distance up to $40 \mathrm{~m}$ assuming indoor environment. The novel architecture was evaluated when assuming full load capacity to prove the architecture effectiveness and successful design to meet high capacity needs.

Therefore, the proposed multi-services RoF architecture is suited for small cell concept and centralized management responding to flexibility needs and high throughput systems for $5 \mathrm{G}$ small cell transport solutions. Although, with the ever increasing of network capacities and control data, implementing robust algorithms that respond to the topology approach, the multi-services applications and the high throughput requirement is highly requested. In future works, we will focus on hierachical optimization algorithms that perform efficient decision under a complex and multi-criteria environment.

\section{References}

[1] LIU, C., ZHANG, L., ZHU, M., et al. A novel multi-service small-cell cloud radio access network for mobile backhaul and computing based on radio-over-fiber technologies. Journal of Lightwave Technology, 2013, vol. 31, no. 17, p. 2869-2875. DOI: 10.1109/JLT.2013.2274193

[2] XU, Z., WANG, H., JI, Y. Multichannel resource allocation mechanism for $60 \mathrm{GHz}$ radio-over-fiber local access networks. Journal of Optical Communications and Networking, 2013, vol. 5, no. 3, p. 254-260. DOI: 10.1364/JOCN.5.000254

[3] REBHI, S., BARRAK, R., HRAGHI, A., et al. High spectral efficiency multi-band radio over fiber system for next generation network. In Proceedings of the IEEE 16th International Conference on Transparent Optical Networks (ICTON). Graz (Austria), 2014, p. 1-4. DOI: 10.1109/ICTON.2014.6876479

[4] KURI, T., OLMOS, J.J.V., KITAYAMA, K. Photonic dynamic channel allocation in optical-frequency-interleaved DWDM millimeterwave-band radio-over-fiber access network. In Proceedings of the IEEE International Topical Meeting on Microwave Photonics. Victoria (Canada), 2007, p. 249-252. DOI: 10.1109/MWP.2007.4378185
[5] BAKAUL, M., NIRMALATHAS, A., LIM, C., et al. Efficient multiplexing scheme for wavelength-interleaved DWDM millimeterwave fiber-radio systems. IEEE Photonics Technology Letters, 2005, vol. 17, no. 12, p. 2718-2720. DOI: 10.1109/LPT.2005.859518

[6] CHANG, G.-K., LIU, C., ZHANG, L. Architecture and applications of a versatile small-cell, multi-service cloud radio access network using radio-over-fiber technologies. In Proceedings of the IEEE International Conference on Communications Workshops (ICC). Budapest (Hungary), 2013. p. 879-883. DOI: 10.1109/ICCW.2013.6649358

[7] LLORENTE, R., WALKER, S., TAFUR MONROY, I., et al. Tripleplay and 60-GHz radio-over-fiber techniques for next-generation optical access networks. In Proceedings of the 16th European Conference on Networks and Optical Communications (NOC). Newcastle-UponTyne (UK), 2011, p. 16-19.

[8] CHANG, G.-K., CHOWDHURY, A., JIA, Z., et al. Key technologies of WDM-PON for future converged optical broadband access networks. Journal of Optical Communications and Networking, 2009, vol. 1, no. 4, p. C35-C50. DOI: 10.1364/JOCN.1.000C35

[9] KIM, H. RoF-based optical fronthaul technology for 5G and beyond. In IEEE Optical Fiber Communications Conference and Exposition (OFC). San Diego (USA), 2018, p. 1-3. DOI: $10.1364 /$ ofc.2018.tu3j.1

[10] NOVAK, D., WATERHOUSE, R. B., Nirmalathas, A., LIM, C., et al. Radio-over-fiber technologies for emerging wireless systems. IEEE Journal of Quantum Electronics, 2016, vol. 52, no. 1, p. 1-11. DOI: 10.1109/JQE.2015.2504107

[11] TZANAKAKI, A., ANASTASOPOULOS, M., BERBERANA, I., et al. Wireless-optical network convergence: Enabling the $5 \mathrm{G}$ architecture to support operational and end-user services. IEEE Communications Magazine, 2017, vol. 55, no. 10, p. 184-192. DOI: 10.1109/MCOM.2017.1600643

[12] GONZALEZ, S., DE LA OLIVA, A., COSTA-PEREZ, X., et al. 5G-crosshaul: An SDN/NFV control and data plane architecture for the $5 \mathrm{G}$ integrated fronthaul/backhaul. Transactions on Emerging Telecommunications Technologies, 2016, vol. 27, no. 9, p. 1196-1205. DOI: 10.1002/ett.3066

[13] Thyagaturu, A. S., MERCiAn, A., MCGARRY, M. P., et al. Software defined optical networks (SDONs): A comprehensive survey. IEEE Communications Surveys \& Tutorials, 2016, vol. 18, no. 4, p. 2738-2786. DOI: 10.1109/COMST.2016.2586999

[14] TZANAKAKI, A., ANASTASOPOULOS, M., BERBERANA, I., et al. Wireless-optical network convergence: Enabling the $5 \mathrm{G}$ architecture to support operational and end-user services. IEEE Communications Magazine, 2017, vol. 55, no. 10, p. 184-192. DOI: 10.1109/MCOM.2017.1600643

[15] QUINLAN, F., YCAS, G., OSTERMAN, S., et al. A 12.5 GHz-spaced optical frequency comb spanning $>400 \mathrm{~nm}$ for astronomical spectrograph calibration. In Proceedings of the Conference on Lasers and Electro-Optics. Optical Society of America. San Jose (USA), 2010, p. 1-2. DOI: $10.1364 /$ cleo.2010.cmhh1

[16] FUKUCHI, Y., HIRATA, K., IKEOKA, H. Wavelength-tunable and bandwidth-variable ultra-flat optical frequency comb block generation from a bismuth-based actively mode-locked fiber laser. IEEE Photonics Journal, 2014, vol. 6, no. 1, p. 1-9. DOI: 10.1109/JPHOT.2013.2295469

[17] BERTHOLD, J. E., ONG, L. Y. Next-generation optical network architecture and multidomain issues. Proceedings of the IEEE, 2012, vol. 100, no. 5, p. 1130-1139. DOI: 10.1109/JPROC.2012.2186213

[18] ZHANG, W., WANG, H., BERGMAN, K. Next-generation optically-interconnected high-performance data centers. Journal of Lightwave Technology, 2012, vol. 30, no. 24, p. 3836-3844. DOI: 10.1109/JLT.2012.2212696 
[19] FUKUSHIMA, Y., JIANG, X., PATTAVINA, A., et al. Self-routing design of nonblocking WDM switches based on arrayed waveguide grating. In Proceedings of the IEEE International Conference on High Performance Switching and Routing. Shanghai (China), 2008, p. 285-290. DOI: 10.1109/HSPR.2008.4734457

[20] ELNDASH, A., MOHAMMED, N. A., RASHED, A. N. Z., et al. Estimated optimization parameters of arrayed waveguide grating (AWG) for C-band applications. International Journal of Physical Sciences, 2009, vol. 4, no. 4, p. 149-155.

[21] ITO, J. TSUDA, H. A compact arrayed-waveguide grating with a locally enhanced optical confinement structure using trenches filled with low-refractive index materials. In Proceedings of the Eur. Conf. Integr. Opt., 2007, 4p.

[22] YIM, J.-N., HWANG, G., LEE, J., et al. Ultra-dense WDM PON with $12.5-\mathrm{GHz}$ spaced 256 channels. Journal of the Optical Society of Korea, 2008, vol. 12, no. 4, p. 351-354. DOI: $10.3807 /$ josk.2008.12.4.351

[23] KAKEHASHI, S., HASEGAWA, H., SATO, K., et al. Analysis and development of fixed and variable waveband MUX/DEMUX utilizing AWG routing functions. Journal of Lightwave Technology, 2009, vol. 27, no. 1, p. 30-40. DOI: 10.1109/JLT.2008.929125

[24] Open Networking Fundation. Software-Defined Networking: The New Norm for Networks (White Paper). 4 pages. [Online] Cited 2012. Available at: https://www.opennetworking.org/images/stories/downloads/sdnresources/white-papers/wp-sdn-newnorm.pdf

[25] FIORANI, M., MONTI, P., SKUBIC, B., et al. Challenges for 5G transport networks. In Proceedings of the IEEE International Conference on Advanced Networks and Telecommuncations Systems (ANTS). New Delhi (India), 2014, p. 1-6. DOI: 10.1109/ANTS.2014.7057286

[26] KIM, B. G., BAE, S. H., KIM, H., et al. Optical fronthaul technologies for next-generation mobile communications. In Proceedings of the 18th International Conference on Transparent Optical Networks (ICTON). Trento (Italy), 2016, p. 1-3. DOI: 10.1109/ICTON.2016.7550604

[27] DAT, P. T., KANNO, A., KAWANISHI, T. Radio-on-radio-overfiber: efficient fronthauling for small cells and moving cells. IEEE Wireless Communications, 2015, vol. 22, no. 5, p. 67-75. DOI: 10.1109/MWC.2015.7306539

[28] RODRIGUEZ, S., MORALES, A., ROMMEL, S., et al. Real-time measurements of an optical reconfigurable radio access unit for $5 \mathrm{G}$ wireless access networks. In Proceedings of Optical Fiber Communication Conference. Optical Society of America. Los Angeles (USA), 2017, 3p. DOI: 10.1364/ofc.2017.w1c.3

[29] IEEE Standard for Information technology-Local and metropolitan area networks-Specific requirements-Part 11: Wireless LAN Medium Access Control (MAC) and Physical Layer (PHY) Specifications. Available at: https://standards.ieee.org/standard/802.112012.html

[30] IEEE Standard for Air Interface for Broadband Wireless Access Systems. Available at: https://standards.ieee.org/findstds/standard/802.16-2012.html

[31] IEEE Standard for Information technology-Telecommunications and information exchange between systems-Local and metropolitan area networks-Specific requirements-Part 11: Wireless LAN Medium Access Control (MAC) and Physical Layer (PHY) Specifications Amendment 3: Enhancements for Very High Throughput in the $60 \mathrm{GHz}$ Band. Available at: https://standards.ieee.org/standard/802.11ad-2012.html.

[32] CCM team. Introduction to Wi-Fi (802.11 or WiFi). Available at: http://ccm.net/contents/802-introduction-to-wi-fi-802-11-orwifi\#q=Introduction+to $+\mathrm{Wi}-\mathrm{Fi}+\&$ cur $=1 \&$ url $=\% 2 \mathrm{~F}$
[33] REBHI, S., BARRAK, R., MENIF, M. Optic/RF co-design for oudoor RoF system at $60 \mathrm{GHz}$. In Proceedings of IEEE 13th Mediterranean Microwave Symposium (MMS). Saida (Lebanon), 2013, p. 1-4. DOI: 10.1109/MMS.2013.6663095

[34] HRAGHI, A., MENIF, M., BEN ABID, S. Optimization of optical flat comb source based on dual-arm Mach-Zehnder modulator for flexgrid terabit superchannel WDM-Nyquist systems. In Proceedings of IEEE 16th International Conference on Transparent Optical Networks (ICTON). Graz (Austria), 2014, p. 1-4. DOI: 10.1109/ICTON.2014.6876483

[35] L-Com. Hyperlink Wireless $2.4 \mathrm{Ghz} 802.11 \mathrm{~b}$ and $802.11 \mathrm{~b}$ Compatible 8 Pole Ultra High Q Outdoor Wifi Bandpass Filter (datasheet). 3 pages. Available at: http://www.l-com.com/bandpassfilter-rf-splitter-24-ghz-ultra-high-q-8-pole-outdoor-bandpass-filterchannel-11-2462-mhz

[36] SST. SST12LPOO 2.4-2.5 Ghz power amplifier (datasheet). 14 pages. [Online] Cited 2009-04. Available at: http://www.mouser.com/ds/2/268/S71283-477580.pdf

[37] Yageo. 5Ghz EIA 0603 Low Profile Band Pass Filter (datasheet). 6 pages. [Online] Cited 2013-01. Available at: https://eu.mouser.com/Passive-Components/SignalConditioning/Datasheets/-/N-8bzui?P=1yzui8wZ1z0s2ciZ1yaf9oe

[38] Stealth microwave. Model SMTR4852-11G36-RSS 6W BiDirectional Power Amplifier (datasheet). 3 pages. Available at: http://www.datasheetlib.com/datasheet/1145263/smtr485211g36-rss-stealth-microwave.html

[39] ZDA. 2.4/5 Ghz External Wireless Antenna (datasheet). 3 pages. [Online] Cited 2008. Available at: http://www.zdacomm.com/2-4-5-ghzdual-band-external-wireless-antenna.html

[40] YANG, B., SKAFIDAS, E., EVANS, R. J. Design of $60 \mathrm{GHz}$ millimetre-wave bandpass filter on bulk CMOS. IET microwaves, antennas \& propagation, 2009, vol. 3, no. 6, p. 943-949. DOI: 10.1049/iet-map.2008.0222

[41] PFEIFFER, U. R., GOREN, D. A $20 \mathrm{dBm}$ fully-integrated $60 \mathrm{GHz}$ $\mathrm{SiGe}$ power amplifier with automatic level control. IEEE Journal of Solid-State Circuits, 2007, vol. 42, no. 7, p. 1455-1463. DOI: $10.1109 /$ JSSC.2007.899116

[42] HEYDARI, B., BOHSALI, M., ADABI, E., et al. A $60 \mathrm{GHz}$ power amplifier in 90nm CMOS technology. In IEEE Custom Integrated Circuits Conference (CICC). San Jose (USA), 2007, p. 769-772. DOI: $10.1109 /$ CICC.2007.4405843

[43] ZHANG, B.,ZHANG, Y. P. Grid array antennas with subarrays and multiple feeds for $60-\mathrm{GHz}$ radios. IEEE Transactions on Antennas and Propagation, 2012, vol. 60, no. 5, p. 2270-2275. DOI: 10.1109/TAP.2012.2189733

[44] REBHI, S., BARRAK, R., MENIF, M., et al. Performance evaluation of radio over fiber system at $60 \mathrm{GHz}$ for outdoor and indoor environments. In Proceedings of the IEEE International Conference on Multimedia Computing and Systems (ICMCS). Marrakech (Morocco), 2014, p. 1418-1421. DOI: 10.1109/ICMCS.2014.6911196

[45] LIU, D., AKKERMANS, J., FLOYD, B. A superstrate patch antenna for 60-GHz applications. In Proceedings of the IEEE European Conference on Antennas and Propagation (EuCAP). Berlin (Germany), 2009, p. 2592-2594.

[46] ALVARADO, J., KORNEGAY, K. T., DAWN, D., et al. 60-GHz LNA using a hybrid transmission line and conductive path to ground technique in silicon. In Proceedings of the IEEE Radio Frequency Integrated Circuits Symposium (RFIC). Honolulu (USA), 2007, p. 685-688. DOI: 10.1109/RFIC.2007.380975 
[47] ZHANG, F., SKAFIDAS, E., SHIEH, W. A 60-GHz double-balanced Gilbert cell down-conversion mixer on 130-nm CMOS. In Proceedings of the IEEE Radio Frequency Integrated Circuits (RFIC). Honolulu (USA), 2007, p. 141-144. DOI: 10.1109/RFIC.2007.380851

[48] BORREMANS, J., DEHAN, M., SCHEIR, K., et al. VCO design for $60 \mathrm{GHz}$ applications using differential shielded inductors in 0.13 Î'm CMOS. In Proceedings of the IEEE Radio Frequency Integrated Circuits Symposium (RFIC). Atlanta (USA), 2008, p. 135-138. DOI: 10.1109/RFIC.2008.4561403

[49] HP. Silicon Bipolar MMIC $1.5 \quad$ Ghz Variable Gain Amplifier (datasheet). 4 pages. Available at: http://www.hp.woodshot.com/hprfhelp/4downld/products/rfics/iva05228.pdf

[50] Apissys. AV101, 10-Bit 10 GSPS ADC and Signal Processing $3 U$ VPX Board (datasheet). 4 pages. Available at: http://www.apissys.com/views/media-produit/datasheets/3/AV101$0 . p d f$

[51] LU, W.-J., LIU, G.-M., TONG, K. F., et al. Dual-band loop-dipole composite unidirectional antenna for broadband wireless communications. IEEE Transactions on Antennas and Propagation, 2014, vol. 62, no. 5, p. 2860-2866. DOI: 10.1109/TAP.2014.2307343

[52] LEE, J., LIM, Y. A dual-band bandpass filter using dual and triple-mode resonators. In IEEE Radio and Wireless Symposium (RWS). Santa Clara (USA), 2012, p. 143-146. DOI: $10.1109 /$ RWS.2012.6175328
[53] AKHCHAF, I., KHOULJI, S., ESSAAIDI, M., et al. A singlechip tri-band low-noise amplifier for cellular transceiver in the wireless applications. In Proceedings of the IEEE International Conference on Complex Systems (ICCS). Agadir (Morocco), 2012, p. 1-5. DOI: $10.1109 / \mathrm{ICoCS} .2012 .6458591$

[54] KAO, H.-1., LEE, P.-C., LI, P.-M., et al. A $2.4 / 5 \mathrm{GHz}$ dualband voltage-controlled oscillator using switched resonator. In Proceedings of the IEEE International Conference on Computational Problem-solving (ICCP). Jiuzhai (China), 2013, p. 20-22. DOI: 10.1109/ICCPS.2013.6893505

[55] SHAFIK, R. A., RAHMAN, M. S., ISLAM, A.H.M. R. On the extended relationships among EVM, BER and SNR as performance metrics. In Proceedings of the IEEE International Conference on Electrical and Computer Engineering (ICECE). Dhaka (Bangladesh), 2006, p. 408-411. DOI: 10.1109/ICECE.2006.355657

\section{About the Authors ...}

Sarra REBHI received her M.Sc. in Telecommunication in 2013 from the Higher Engineering School of Communication of Tunis (SupCom), Tunisia and is currently pursuing her Ph.D. at SupCom. Her research interests include optical communication, Radio over Fiber systems and cognitive optical-wireless networks. 